\title{
Ferulic acid ameliorates cerebral infarction by activating Akt/mTOR/4E-BP1/Bcl-2 anti-apoptotic signaling in the penumbral cortex following permanent cerebral ischemia in rats
}

\author{
CHIN-YI CHENG ${ }^{1,2}$, SHUNG-TE KAO ${ }^{3}$ and YU-CHEN LEE ${ }^{4-6}$ \\ ${ }^{1}$ School of Post-Baccalaureate Chinese Medicine, College of Chinese Medicine, China Medical University, Taichung 40402; \\ ${ }^{2}$ Department of Chinese Medicine, Hui-Sheng Hospital, Taichung 42056; ${ }^{3}$ School of Chinese Medicine, \\ College of Chinese Medicine, China Medical University, Taichung 40402; ${ }^{4}$ Department of Chinese Medicine, \\ China Medical University Hospital, Taichung 40447; ${ }^{5}$ Research Center for Chinese Medicine \& Acupuncture; \\ ${ }^{6}$ Graduate Institute of Acupuncture Science, China Medical University, Taichung 40402, Taiwan, R.O.C.
}

Received April 24, 2018; Accepted November 23, 2018

DOI: $10.3892 / \mathrm{mmr} .2018 .9737$

\begin{abstract}
The aim of the present study was to determine the effects of ferulic acid (FerA) administered immediately following the onset of permanent middle cerebral artery occlusion (MCAo) and then 7 days of ischemia, and also to explore the involvement of protein kinase B (Akt)-induced signaling in the penumbral cortex. Immediately following the onset of MCAo, FerA was intravenously administered to rats at a dose of $60 \mathrm{mg} / \mathrm{kg}$ (FerA-60 mg), $80 \mathrm{mg} / \mathrm{kg}$ (FerA-80 mg), or $100 \mathrm{mg} / \mathrm{kg}$ (FerA-100 mg). FerA-80 mg and FerA-100 mg effectively ameliorated cerebral infarction and neurological deficits 7 days following permanent cerebral ischemia. FerA-80 mg and FerA-100 mg significantly upregulated the expression of phospho-Akt (p-Akt), phospho-mammalian target of rapamycin (p-mTOR), and eukaryotic initiation factor $4 \mathrm{E}$ (eIF4E)-binding protein 1 (4E-BP1), and the phospho-4E-BP1 (p-4E-BP1)/4E-BP1 and mitochondrial Bcl-2/Bax ratios, and markedly downregulated the levels of cytochrome $c$-, cleaved caspase-3-, and terminal deoxynucleotidyl transferase-mediated dUTP-biotin nick-end labeling-immunoreactive cells in the penumbral cortex at 7 days post-ischemia. LY294002, a selective inhibitor of phosphoinositide 3-kinase/Akt signaling, was administered $30 \mathrm{~min}$ prior to ischemia, which abrogated the upregulating effects of FerA-100 mg on the expression of p-Akt, p-mTOR, 4E-BP1, p-4E-BP1 and eIF4E, the mitochondrial Bcl-2/Bax ratio and the ameliorating effect of FerA-100 mg on cerebral infarction. FerA administered at doses of 80 and $100 \mathrm{mg} / \mathrm{kg}$
\end{abstract}

Correspondence to: Professor Yu-Chen Lee, Graduate Institute of Acupuncture Science, China Medical University, 91 Hsueh-Shih Road, Taichung 40402, Taiwan, R.O.C.

E-mail: d5167@mail.cmuh.org.tw

Key words: ferulic acid, cerebral ischemia, protein kinase B, mammalian target of rapamycin, apoptosis, eukaryotic initiation factor 4E-binding protein 1 exerted beneficial effects against cerebral ischemia by activating Akt-induced signaling. The effects of FerA at doses of 80 and $100 \mathrm{mg} / \mathrm{kg}$ on mitochondrial B-cell lymphoma-2 (Bcl-2)-associated X protein-related apoptosis were attributed to the activation of Akt/mTOR/4E-BP1/Bcl-2 anti-apoptotic signaling, and eventually contributed to suppression of the cytochrome $c /$ caspase- 3 activation pathway in the penumbral cortex 7 days following permanent cerebral ischemia.

\section{Introduction}

During cerebral ischemia, mitogen-activated protein kinases and phosphoinositide 3-kinase (PI3K)/protein kinase B (Akt) signaling cascades are key in the regulation of cell proliferation, survival and apoptosis, and in the translation of anti-apoptotic factors B-cell lymphoma-2 (Bcl-2) and Bcl-extra-large (Bcl-xL), leading to neuroprotection against ischemic injury (1-4). Three closely related Akt isoforms, namely Akt1, Akt2 and Akt3, directly phosphorylate and activate mammalian target of rapamycin (mTOR) signaling and its downstream effectors in response to activation of the PI3K/Akt signaling pathway (5). Activated Akt (mainly Akt1 and Akt3) protects against ischemia-induced neuronal injury by upregulating the activity of mTOR, which in turn triggers the phosphorylation of Akt in the ischemia region, thus creating a positive feedback loop for the activation of Akt/mTOR signaling following cerebral ischemic injury (6). mTOR is a $289-\mathrm{kDa}$ serine/threonine protein kinase that regulates various cellular activities, including cell proliferation, growth and survival $(7,8)$. Akt/mTOR signaling protects against apoptosis by promoting the expression of anti-apoptotic proteins Bcl-2 and Bcl-xL, and by inhibiting the expression of pro-apoptotic proteins $\mathrm{Bcl}-2$-associated $\mathrm{X}$ protein (Bax) and Bcl-2 antagonist of cell death (Bad) in the ischemic region following focal cerebral ischemia (8). There is compelling evidence that a significant increase in the Bcl-2 (Bcl-xL)/Bax ratio promotes neuronal cell survival following cerebral ischemic-reperfusion (I/R) injury (9). mTOR forms two protein complexes, mTOR Complex 1 (mTORC1) and mTOR Complex 2 (mTORC2), and is involved in the regulation 
of cell growth and metabolism $(7,10)$. mTORC1 function has been investigated extensively, whereas the function of mTORC2 remains to be fully elucidated. The major mTORC1 components include mTOR, proline-rich Akt substrate of $40 \mathrm{kDa}$ and Raptor (11). mTOR activates its downstream target, p70 S6 kinase (p70S6K), which subsequently phosphorylates the 40S ribosomal protein S6 (S6) to control the initiation of translation $(10,11)$. The phosphorylation of S6 is also crucial in the regulation of mRNA translation and protein synthesis (12). The mTOR pathway is activated following ischemic brain injury. Activation of the mTOR/p70S6K/S6 signaling cascade regulates ribosome biogenesis and protein translation, and subsequently exerts neuroprotective effects against infarction following focal cerebral ischemia $(5,11,13)$. By contrast, a decrease in the activity of mTOR has been linked to the induction of apoptosis in in vitro and in vivo models of cerebral ischemia (14).

The family of eukaryoticinitiation factor 4E(eIF4E)-binding proteins (4E-BPs) comprises three members, 4E-BP1, 4E-BP2 and $4 \mathrm{E}-\mathrm{BP} 3$. As another downstream target of mTOR, 4E-BP1 is a translational repressor that binds to eIF4E and thereby inhibits its interaction with eIF4G $(15,16)$. The availability of eIF4E is a rate-limiting step in the initiation of translation and is an important factor in the regulation of gene expression. The interaction between 4E-BP1 and eIF4E inhibits protein synthesis; however, protein synthesis is essential for neuronal cell survival following cerebral ischemic insults (16). The phosphorylation of 4E-BP1 by mTOR causes its dissociation from eIF4E, leading to the subsequent formation of an eIF4E-eIF4G complex and thereby promoting anti-apoptotic protein translation (7). Activation of the Akt/mTOR/4E-BP1 signaling pathway significantly ameliorates cerebral infarction and improves neurological outcomes following ischemic postconditioning in rats, and the beneficial effects can be attributed to the inhibition of mitochondria-mediated apoptosis $(11,17)$.

Ferulic acid (4-hydroxy-3-methoxycinnamic acid, FerA) is a major active ingredient derived from Angelica sinensis (Oliv.) Diels (1). In traditional Chinese medicine, $A$. sinensis has been used for centuries to improve blood circulation and as a treatment for stroke (18-20). Our previous studies demonstrated that FerA exerts neuroprotective effects against cerebral I/R injury by downregulating the inflammatory response and oxidative stress in the ischemic region during the acute phase $(21,22)$, and by inhibiting apoptosis in the penumbral cortex during the subacute phase (1) following transient middle cerebral artery occlusion (MCAo). Other studies have shown that FerA prevents ischemia-induced apoptosis by phosphorylating $\mathrm{Akt} / \mathrm{Bad}$ or Akt/phosphoprotein enriched in astrocytes-15 signaling in the acute phase of permanent MCAo $(23,24)$. However, the precise mechanisms underlying the neuroprotective effects of FerA on cerebral ischemic injury in the subacute phase of permanent MCAo remain to be elucidated.

Therefore, the present study evaluated the effects of various doses of FerA administered 7 days following permanent MCAo and examined the involvement of Akt signaling cascades in the penumbral cortex.

\section{Materials and methods}

Experimental animals. A total of 106 male Sprague-Dawley (SD) rats (BioLASCO Taiwan Co., Ltd., Taipei, Taiwan),
8-9 weeks of age and weighing 300-350 g, were used in the present study. The rats were housed in standard plastic cages, fed a constant provision of solid food, provided with water ad libitum, and maintained in 12-h light-dark cycles under a relative humidity of $55 \pm 5 \%$ at $22 \pm 2^{\circ} \mathrm{C}$. All study procedures were approved by the Institutional Animal Care and Use Committee of China Medical University (Taichung, Taiwan; permit no. 2016-321).

Permanent MCAo. The permanent MCAo model was performed on adult SD rats as described previously with modifications (25). The rats were initially anesthetized with $5 \%$ isoflurane in a plastic chamber. Subsequently, general anesthesia was maintained using a $2 \%$ isoflurane-oxygen mixture delivered via facemask inhalation. The anesthetized rat was removed from the plastic chamber, and its head was fixed on the stereotactic frame. Following dissecting the scalp, a burr hole was drilled into the skull $2.5 \mathrm{~mm}$ lateral and $2.0 \mathrm{~mm}$ posterior to the bregma in order to expose the right distal end of the MCA. The rat was placed in the supine position, and a neck incision was performed to expose the right common, external carotid artery (ECA) and internal carotid artery (ICA). A 3-0 nylon suture was inserted from the ECA into the ICA for a distance of 21-22 mm. During MCAo, the blood flow in the MCA was continually evaluated using laser Doppler flowmetry (DRT4, Moor Instruments, Inc., Devon, UK) through the burr hole in the skull. Blood flow reduction to $20-25 \%$ of the pre-ischemic value was used to validate the success of the permanent MCAo model.

Evaluation of neurological functions. The neurological status of each rat was examined 1, 3, and 7 days following cerebral ischemia using a modified neurological deficit score (NDS; score of 0-18) as described previously (26). A laboratory assistant blinded to the group assignment evaluated the items of neurological examination, which included motor, sensory, balance and reflex tests.

\section{Experiment $A$}

Grouping. The rats were randomly divided into five groups: Sham, Vehicle, FerA-60 mg, FerA-80 mg, and FerA-100 mg groups $(\mathrm{n}=4-5)$. In the FerA-60 mg, FerA-80 mg, and FerA-100 mg groups, the rats underwent MCAo surgery and were simultaneously administered FerA intravenously (iv) at doses of 60,80 and $100 \mathrm{mg} / \mathrm{kg}$, respectively. Following 7 days of cerebral ischemia, the rats were examined for neurological functions and then sacrificed. In the Vehicle group, the rats underwent the same procedures as that of the FerA-100 mg group, but the rats were administered saline instead of FerA. In the Sham group, the rats underwent the same procedures as that of the Vehicle group; however, the rats did not undergo MCAo.

Evaluation of cerebral infarct area. Following 7 days of cerebral ischemia, the rats were examined for their neurological status and subsequently sacrificed. Their brains were carefully removed from the skull and divided into six serial 2 -mm thick coronal slices using a brain slicer matrix. The brain slices were placed in a constant temperature box and incubated with $2 \%$ solution of 2,3,5-triphenyltetrazolium chloride (TTC; Merck KGaA, Darmstadt, Germany) for 5 min 
at $37^{\circ} \mathrm{C}$. Following TTC staining, the cerebral infarct in the MCA territory turned pale white, whereas the healthy brain tissue turned dark red. The TTC stained brain sections were visualized and photographed using a digital camera (Nikon Coolpix 775; Nikon Corporation, Tokyo, Japan). The areas of infarction were evaluated using image analysis software (ImageJ version 1.46; National Institutes of Health, Bethesda, MD, USA), and the percentage of cerebral infarction was obtained by determining the ratio of the cerebral infarct area to the total brain area.

\section{Experiment $B$}

Grouping. The rats were randomly divided into the following five groups: Sham, Vehicle, FerA-60 mg, FerA-80 mg, and FerA-100 mg groups $(n=4-5)$. They underwent the same procedures as described in Experiment A.

Western blot analysis. Following 7 days of cerebral ischemia, the rats were sacrificed and their brains were carefully removed. The coronal sections of the brains obtained from $1.7 \mathrm{~mm}$ anterior to $4.3 \mathrm{~mm}$ posterior to the bregma were used for western blot analysis. The penumbral cortex was homogenized in cold Cytosol Extraction Buffer mix (BioVision, Inc., Milpitas, CA, USA) using a tissue homogenizer (Kinematia Polytron RT-3000). The samples were further divided into cytosolic and mitochondrial fractions using the Mitochondria/Cytosol Fractionation kit (cat. no. K256-100 BioVision, Inc.). The concentrations of the cytosolic and mitochondrial proteins were evaluated using a Bio-Rad protein assay. Equal quantities (15 $\mu \mathrm{g} /$ well) of protein were loaded into the gel wells and separated according to their molecular weight by $10 \%$ sodium dodecyl sulfate-polyacrylamide gel electrophoresis, as described previously (27). Subsequently, the gel-separated proteins were transferred onto nitrocellulose (NC) membranes. Based on the molecular weight marker, the NC membranes were carefully split into pieces and incubated with the following primary antibodies: Akt (rabbit, cat. no. 4685; Cell Signaling Technology, Inc., Danvers, MA, USA, 1:1,000), p-Akt (rabbit, cat. no. 9271; Cell Signaling Technology, Inc., 1:1,000), mTOR (rabbit, cat. no. 2972; Cell Signaling Technology, Inc., 1:1,000), p-mTOR (rabbit, cat. no. 2971; Cell Signaling Technology, Inc., 1:1,000), 4E-BP1 (rabbit, cat. no. 9644; Cell Signaling Technology, Inc., 1:1,000), p-4E-BP1 (rabbit, cat. no. 2855; Cell Signaling Technology, Inc., 1:1,000), p70S6K (rabbit, cat. no. 9202; Cell Signaling Technology, Inc., 1:1,000), p-p70S6K (rabbit, cat. no. 9208; Cell Signaling Technology, Inc., 1:1,000), Bcl-2 (rabbit, cat. no. 2876; Cell Signaling Technology, Inc., 1:1,000), Bax (rabbit, cat. no. 2772; Cell Signaling Technology, Inc., 1:1,000), Bcl-xL (rabbit, cat. no. 2762; Cell Signaling Technology, Inc., 1:1,000), actin (mouse, cat. no. NB600-501; Novus Biologicals, LLC, Littleton, CO, USA, 1:5,000) and heat shock protein 60 (HSP60; rabbit, cat. no. 4870, Cell Signaling Technology, Inc., 1:1,000) overnight at $4^{\circ} \mathrm{C}$. The membranes were subsequently incubated with an anti-rabbit horseradish peroxidase (HRP)-conjugated Immunoglobulin G (IgG; cat. no. 123450; Jackson ImmunoResearch Laboratories, Inc., West Grove, PA, USA) or anti-mouse HRP-conjugated IgG (cat. no. 127442; Jackson ImmunoResearch Laboratories, Inc.) secondary antibody for $1 \mathrm{~h}$ at room temperature. Densitometric analyses were performed using analysis software (ImageJ). The immunoblotting results were determined as the optical density ratios of target proteins to actin or phosphorylated proteins to non-phosphorylated proteins.

Immunohistochemical (IHC) analysis. Following 7 days of ischemia, the rats were sacrificed $(n=3-4)$. Their brains were carefully removed, postfixed in $4 \%$ paraformalaldehyde, and cut into $15-\mu \mathrm{m}$-thick sections, as described previously (28). The brain sections were then incubated with primary antibodies overnight at $4^{\circ} \mathrm{C}$ to detect the expression of cytochrome $c$ (rabbit; cat. no. 10993-1-AP; ProteinTech Group, Inc., Chicago, IL, USA, 1:50) and cleaved caspase-3 (rabbit; cat. no., 9664; Cell Signaling Technology, Inc., 1:100). Following incubation with the primary antibodies, the sections were subsequently incubated with the appropriate secondary antibody-avidin-biotin peroxidase complexes (Leica Biosystems, Newcastle Ltd., Newcastle, UK), 3,3'-diaminobenzidine (Leica Biosystems Newcastle, Ltd.) and hematoxylin (Merck KGaA). The immunoreactive cells in the penumbral cortex were detected under a light microscope (Axioskop 40; Carl Zeiss AG, Oberkochen, Germany). The brain sections obtained from the rats of the Vehicle group that were stained without primary antibodies were used as negative controls.

Terminal deoxynucleotidyl transferase-mediated dUTP-biotin nick-end labeling (TUNEL) assay. TUNEL staining was performed in accordance with the manufacturer's protocol (QIA33; Calbiochem; Merck KGaA). The brain slides of the adjacent sections used in IHC analysis were first incubated with $20 \mu \mathrm{g} / \mathrm{ml}$ proteinase $\mathrm{K}$ for $20 \mathrm{~min}$ at room temperature, as described previously (29). The TUNEL-reactive cells in the penumbral cortex were examined under a light microscope.

\section{Experiment $C$}

Grouping. The rats were randomly divided into four groups: DS + Sham, DS + Vehicle, DS + FerA-100 mg, and LY + FerA-100 mg groups (n=4-5). In the LY + FerA-100 mg group, the rats underwent the same surgical procedures as that of the FerA-100 mg group (Experiment A); however, the rats also received an intracerebroventricular (ICV) infusion of LY294002 (LY), a PI3K/Akt inhibitor, 30 min prior to MCAo. In the DS + FerA-100 mg group, the rats underwent the same surgical procedures as that of the LY + FerA-100 mg group, but the rats received an ICV infusion of $1 \%$ dimethyl sulfoxide (DMSO). In the DS + Vehicle group, the rats underwent the same surgical procedures as that of the Vehicle group (Experiment A), but the rats also received an ICV infusion of 1\% DMSO 30 min prior to MCAo. In the DS + Sham group, the rats underwent the same surgical procedures as that of the DS + Vehicle group, but the rats did not undergo MCAo.

ICV infusion of LY or $1 \%$ DMSO. The rats were anesthetized with $5 \%$ isoflurane, and anesthesia was maintained via facemask inhalation using $2 \%$ isoflurane. The rats received an ICV infusion of $10 \mu \mathrm{l}$ of a solution containing LY (10 mM in DMSO, cat. no. 1747-5, BioVision, Inc.) or 1\% DMSO into their right hemisphere. The infusions were performed over a 6-min period using a $10 \mu$ l Hamilton microliter syringe (Hamilton Company, Reno, NV, USA). The infusion was administered into the right 

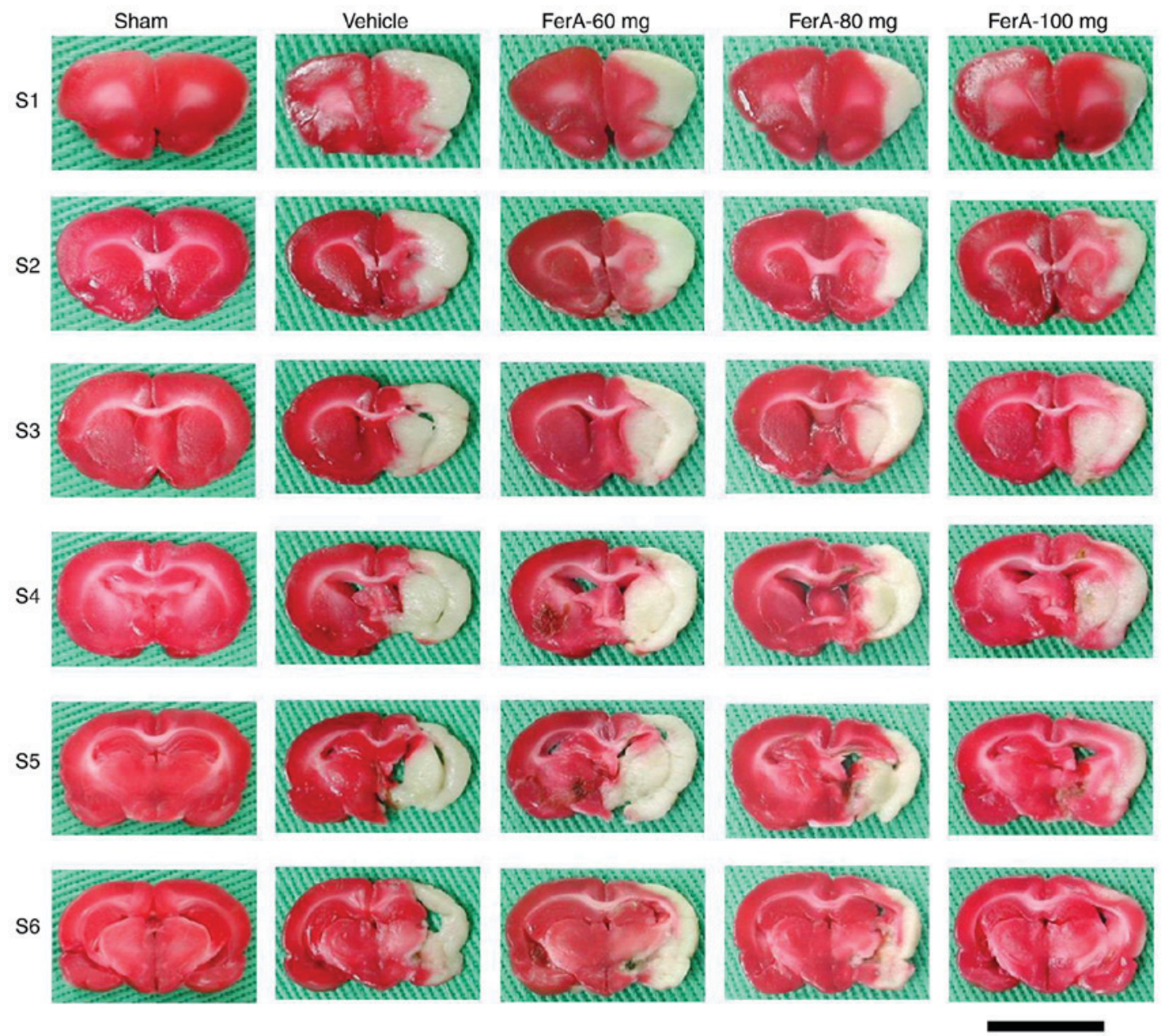

Figure 1. Cerebral infarct areas (S1-S6) in the experimental groups at 7 days following cerebral ischemia. In 2,3,5-triphenyltetrazolium chloride-stained sections, infarction is represented by a pale white color and non-infarction is represented by a dark red color. Scale bar=1 cm. FerA, ferulic acid.

cerebral ventricle $(0.8 \mathrm{~mm}$ posterior to the bregma, $1.5 \mathrm{~mm}$ lateral on the right side, and $3.5 \mathrm{~mm}$ below the skull surface).

Western blot analysis. Following 7 days of ischemia, the rats were sacrificed, and their brains were immediately removed for incubation with antibodies for western blot analysis of the expression of Akt, p-Akt, mTOR, p-mTOR, 4E-BP1, p-4E-BP1, eIF4E (rabbit, cat. no. 9742; Cell Signaling Technology, Inc., 1:1,000), Bcl-2 and Bax. The protocol used for analysis of the protein samples using western blotting was the same as that described for Experiment B.

\section{Experiment D}

Grouping. The rats were randomly divided into the following four groups: DS + Sham, DS + Vehicle, DS + FerA-100 mg, and LY + FerA-100 mg groups $(n=3-4)$. They underwent the same experimental protocols as described in Experiment $\mathrm{C}$.

Evaluation of cerebral infarct area. At 7 days post-ischemia, the rats were sacrificed. They underwent the same experimental protocols for cerebral infarct detection as described in Experiment A.

Statistical analysis. All data in the present study are expressed as the mean \pm standard deviation. Comparisons were performed using one-way analysis of variance with a Scheffe post hoc test. $\mathrm{P}<0.05$ was considered to indicate a statistically significant difference. All data were analyzed using SPSS 13.0 software (SPSS, Inc., Chicago, IL, USA).

\section{Results}

Effects of FerA treatment on cerebral infarct area. At 7 days post-ischemia, the percentage of the cerebral infarct area was significantly increased in the Vehicle group compared with that in the Sham group $(\mathrm{P}<0.05)$ and was significantly reduced in the FerA-80 mg and FerA-100 mg groups compared with that in the Vehicle group (both $\mathrm{P}<0.05$; Figs. 1 and $2 \mathrm{~A}$ ). However, no significant difference was found in the percentage of cerebral infarct area between the Vehicle and FerA-60 mg groups $(\mathrm{P}>0.05)$.

Effects of FerA treatment on neurological function. At 1 day post-ischemia, the NDS of the Vehicle, FerA-60 mg, FerA-80 mg, and FerA-100 mg groups did not differ significantly ( $\mathrm{P}>0.05$; Fig. 2B). At 3 days post-ischemia, the NDS of the FerA-100 mg group was significantly reduced compared with that of the Vehicle group ( $\mathrm{P}<0.05$; Fig. 2B). No significant differences were observed in the NDS among the Vehicle, FerA-60 mg and FerA-80 mg groups (P>0.05). At 7 days 

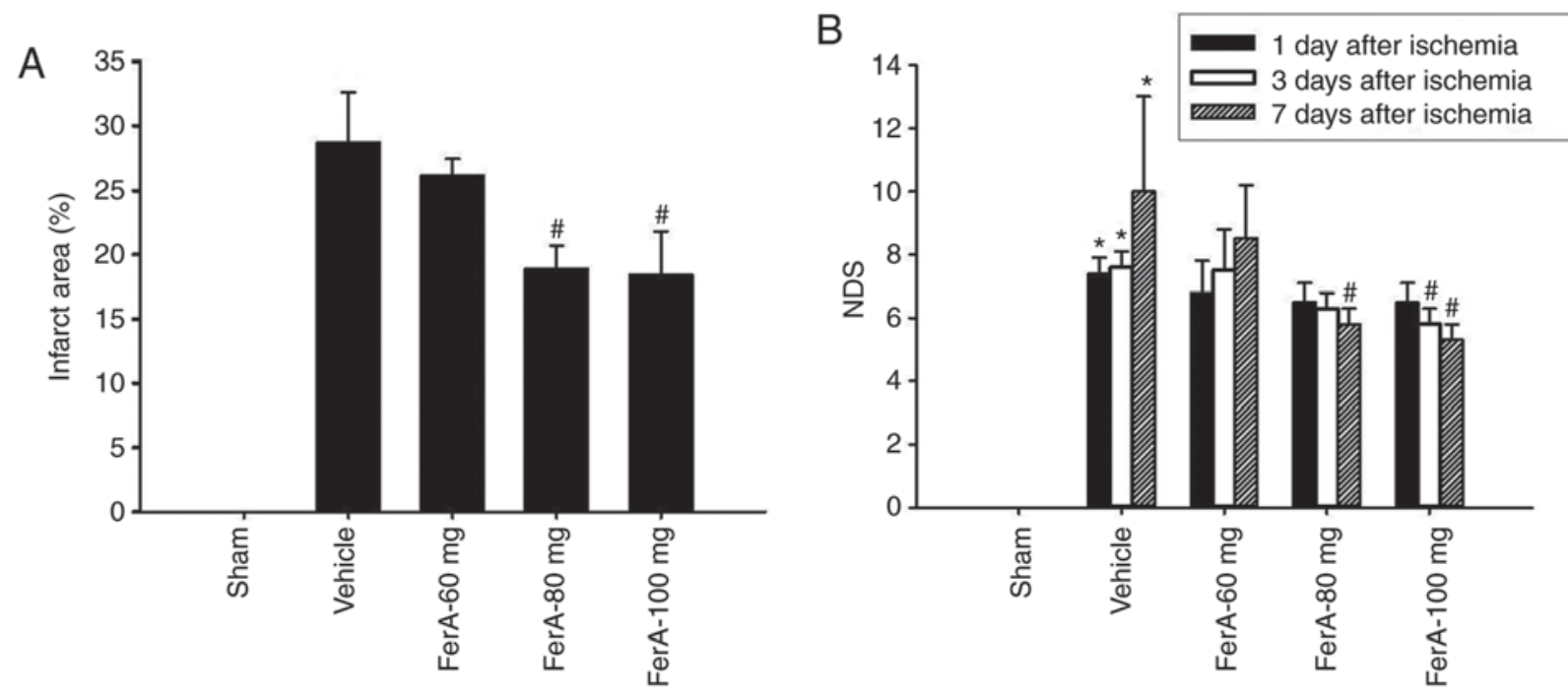

Figure 2. Effects of FerA treatment on cerebral infarct area and neurological deficits 7 days following cerebral ischemia. (A) Percentages of cerebral infarct areas in the Sham, Vehicle, FerA- $60 \mathrm{mg}$, FerA- $80 \mathrm{mg}$, and FerA-100 mg groups were evaluated at 7 days post-ischemia $(\mathrm{n}=4-5)$. (B) NDS of the Sham, Vehicle, FerA- $60 \mathrm{mg}$, FerA- $80 \mathrm{mg}$, and FerA-100 mg groups were evaluated at 1,3, and 7 days post-ischemia. ${ }^{*} \mathrm{P}<0.05$ vs. the Sham group; ${ }^{*} \mathrm{P}<0.05$ vs. the Vehicle group. FerA, ferulic acid; NDS, neurological deficit score.

post-ischemia, the NDS of the FerA-80 mg and FerA-100 mg groups were significantly reduced compared with that of the Vehicle group (both $\mathrm{P}<0.05$; Fig. 2B), whereas the NDS of the Vehicle and the FerA-60 mg groups did not differ significantly $(\mathrm{P}>0.05)$.

Effects of FerA treatment on the cytosolic expression of $p$-Akt, Akt, p-mTOR, mTOR, $p-4 E-B P 1,4 E-B P 1, p-p 70 S 6 K$, and $p 70 S 6 K$. The results of the western blot analysis showed that the ratios of cytosolic p-Akt/Akt and p-mTOR/mTOR expression in the penumbral cortex were significantly reduced in the Vehicle group (both 0.3 -fold) compared with those in the Sham group (both $\mathrm{P}<0.05$ ) and were significantly increased in the FerA- $80 \mathrm{mg}$ (3.4- and 5.1-fold, respectively) and FerA-100 mg (5.0- and 5.1-fold, respectively) groups compared with the Vehicle group (all $\mathrm{P}<0.05$; Fig. 3A-C) at 7 days post-ischemia. The ratios of cytosolic p-Akt/Akt and p-mTOR/mTOR expression in the Vehicle and FerA-60 mg groups did not differ significantly $(\mathrm{P}>0.05)$. The ratio of cytosolic 4E-BP1/actin expression was significantly reduced in the Vehicle group (0.4-fold) compared with that in the Sham group $(\mathrm{P}<0.05)$ and was significantly increased in the FerA-80 mg (2.6-fold) and FerA-100 mg (2.9-fold) groups compared with that in the Vehicle group (both $\mathrm{P}<0.05$; Fig. $3 \mathrm{~A}$ and $\mathrm{D}$ ). The ratios of cytosolic 4E-BP1/actin expression in the Vehicle and FerA-60 mg groups did not differ significantly ( $>0.05$ ). The ratios of cytosolic p-4E-BP1/4E-BP1 expression were significantly increased in the FerA- $80 \mathrm{mg}$ (13.3- and 2.4-fold, respectively) and FerA-100 mg (11.7- and 2.1-fold, respectively) groups compared with those in the Sham and Vehicle groups (all $\mathrm{P}<0.05$; Fig. 3A and $\mathrm{E}$ ). The ratios of cytosolic p-4E-BP1/4E-BP1 expression in the Sham, Vehicle, and FerA-60 mg groups did not differ significantly $(\mathrm{P}>0.05)$. The ratios of cytosolic p70S6K/actin and p-p70S6K/p70S6K expression in the penumbral cortex among the Sham, Vehicle, and FerA-treated groups did not differ significantly $(\mathrm{P}>0.05$; Fig. 3A, F and G).
Effects of FerA treatment on the ratio of mitochondrial expression of Bcl-2, Bcl-xL and Bax. The ratio of mitochondrial Bcl-2/Bax expression in the penumbral cortex was markedly reduced in the Vehicle group ( 0.2 -fold) compared with that in the Sham group $(\mathrm{P}<0.05)$ and was markedly increased in the FerA- $80 \mathrm{mg}$ (10.5-fold) and FerA-100 mg (11.6-fold) groups compared with that in the Vehicle group (both $\mathrm{P}<0.05$; Fig. $4 \mathrm{~A}$ and $\mathrm{B}$ ) at 7 days post-ischemia. The ratios of mitochondrial $\mathrm{Bcl}-2 / \mathrm{Bax}$ expression in the Vehicle and FerA-60 mg groups did not differ significantly ( $\mathrm{P}>0.05$ ). No significant differences were observed in the ratio of mitochondrial Bcl-xL/Bax expression among the Sham, Vehicle and FerA-treated groups ( $\mathrm{P}>0.05$; Fig. $4 \mathrm{~A}$ and $\mathrm{C})$.

Effects of FerA treatment on the expression of cytochrome c-, cleaved caspase-3-, and TUNEL-immunoreactive cells. The numbers of cytochrome $c$-, cleaved caspase-3-, and TUNEL-immunoreactive cells in the penumbral cortex were calculated (counts $/ 1 \mathrm{~mm}^{2}$ ) at 7 days post-ischemia. The numbers of cytochrome $c$-, cleaved caspase-3-, and TUNEL-immunoreactive cells were significantly increased in the Vehicle group compared with those in the Sham group (all $\mathrm{P}<0.05$ ) and were significantly reduced in the FerA- $80 \mathrm{mg}$ and FerA-100 mg groups compared with those in the Vehicle group (all $\mathrm{P}<0.05$; Fig. 5A-C; Table I). No significant differences were observed in the numbers of cytochrome c-, cleaved caspase-3-, and TUNEL-immunoreactive cells between the Vehicle and FerA-60 mg groups $(\mathrm{P}>0.05)$. The penumbral cortex region in which cells were counted is indicated in Fig. 5D.

Effects of DS + FerA-100 mg and LY + FerA-100 mg on the ratios of cytosolic expression of p-Akt/Akt, p-mTOR/mTOR, p-4E-BPl/actin, 4E-BPl/actin, and eIF4E/actin. The ratios of cytosolic p-Akt/Akt, p-mTOR/mTOR, 4E-BP1/actin, and eIF4E/actin expression in the penumbral cortex were significantly reduced in the DS + Vehicle group (0.4-, 0.3-, 0.4-, and 0.2 -fold, respectively) compared with those in the DS + Sham 

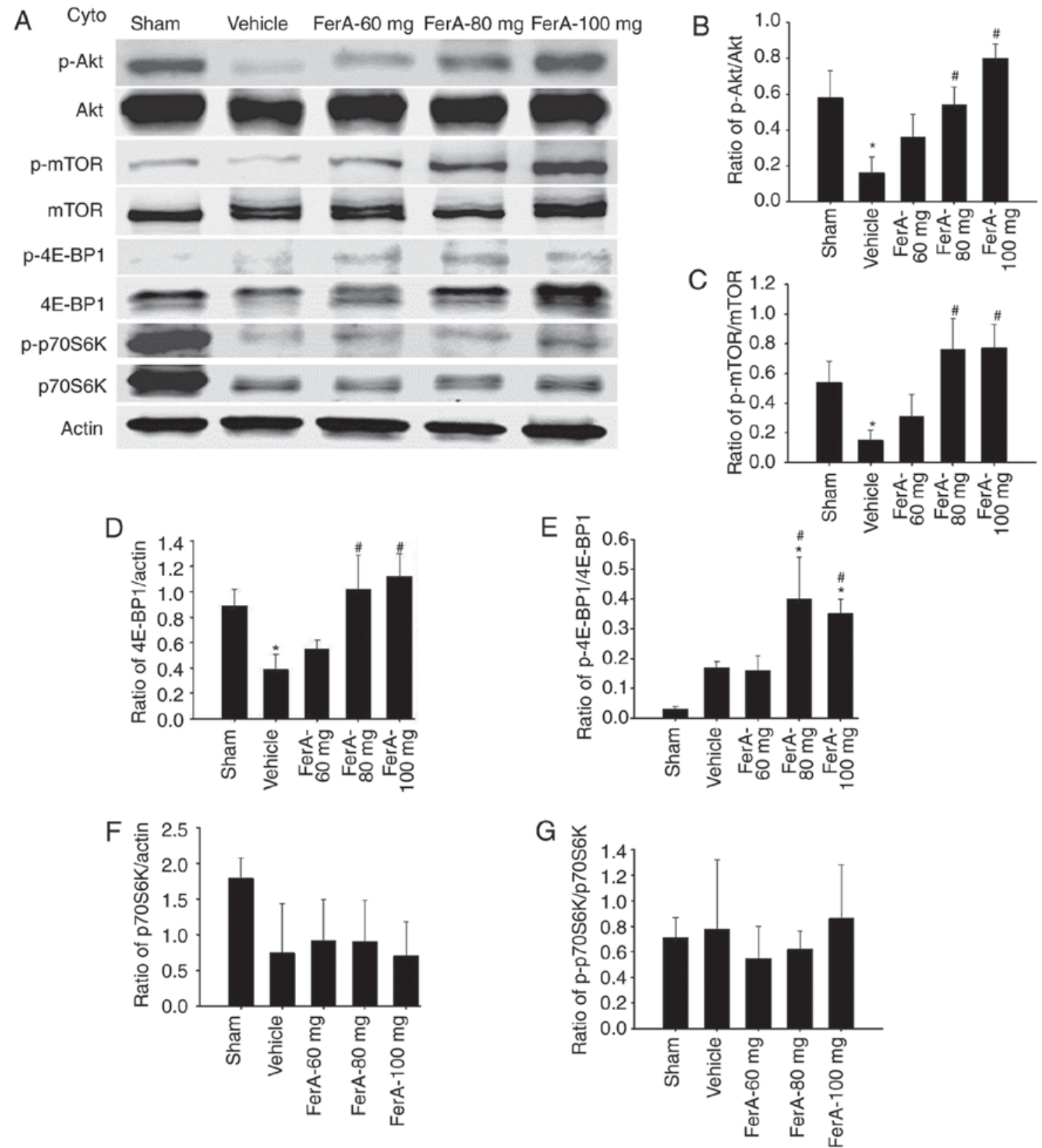

Figure 3. Effects of FerA treatment on the cytosolic expression of p-Akt, Akt, p-mTOR, mTOR, p-4E-BP1, 4E-BP1, p-p70S6K, and p70S6K in the penumbral cortex. (A) Representative western blot images revealed the cytosolic expression of p-Akt, Akt, p-mTOR, mTOR, p-4E-BP1, 4E-BP1, p-p70S6K, and p70S6K in the penumbral cortex of the Sham, Vehicle, FerA- $60 \mathrm{mg}$, FerA- $80 \mathrm{mg}$, and FerA-100 mg groups at 7 days post-ischemia. Actin was used as an internal control for cytosolic extracts. The ratios of (B) p-Akt/Akt, (C) p-mTOR/mTOR, (D) 4E-BP1/actin, (E) p-4E-BP1/4E-BP1, (F) p70S6K/actin, and (G) p-p70S6K/p70S6K expression were measured in the penumbral cortex in the Sham, Vehicle, FerA-60 mg, FerA-80 mg, and FerA-100 mg groups ( $\mathrm{n}=4-5)$. " $\mathrm{P}<0.05$ vs. the Sham group; " $\mathrm{P}<0.05$ vs. the Vehicle group. FerA, ferulic acid; cyto, cytosolic fraction; mTOR, mammalian target of rapamycin; 4E-BP1, eukaryotic initiation factor 4E-binding protein 1; p-, phosphorylated.

group (all $\mathrm{P}<0.05)$ and were significantly increased in the DS + FerA-100 mg group (3.2-, 3.7-, 3.5-, and 3.3-fold, respectively) compared with those in the DS + Vehicle group (all $\mathrm{P}<0.05$ Fig. 6A-E) at 7 days post-ischemia. No significant differences were observed in the ratios of cytosolic p-Akt/Akt, p-mTOR/mTOR, 4E-BP1/actin and eIF4E/actin expression between the DS + Vehicle and LY + FerA-100 mg groups $(\mathrm{P}>0.05)$. The ratio of cytosolic $\mathrm{p}-4 \mathrm{E}-\mathrm{BP} 1 /$ actin expression was significantly increased in the DS + FerA-100 mg group (11.8- and 4.7-fold, respectively) compared with the ratios in the DS + Sham and DS + Vehicle groups (both $\mathrm{P}<0.05$; Fig. 6A and F). No significant differences were observed in the ratios of cytosolic p-4E-BP1/actin expression among the DS + Sham, DS + Vehicle, and LY + FerA-100 mg groups $(\mathrm{P}>0.05)$.

Effects of DS + FerA-100 mg and LY + FerA-100 mg on the ratio of mitochondrial expression of Bcl-2/Bax. The ratio of mitochondrial Bcl-2/Bax expression in the penumbral cortex was markedly reduced in the DS + Vehicle group (0.2-fold) compared with that in the DS + Sham group $(\mathrm{P}<0.05)$ and was markedly increased in the DS + FerA-100 mg group (3.5-fold) compared with that in the DS + Vehicle group $(\mathrm{P}<0.05$; Fig. 7A and B) at 7 days post-ischemia. No significant differences were observed in the ratios of mitochondrial Bcl-2/Bax 

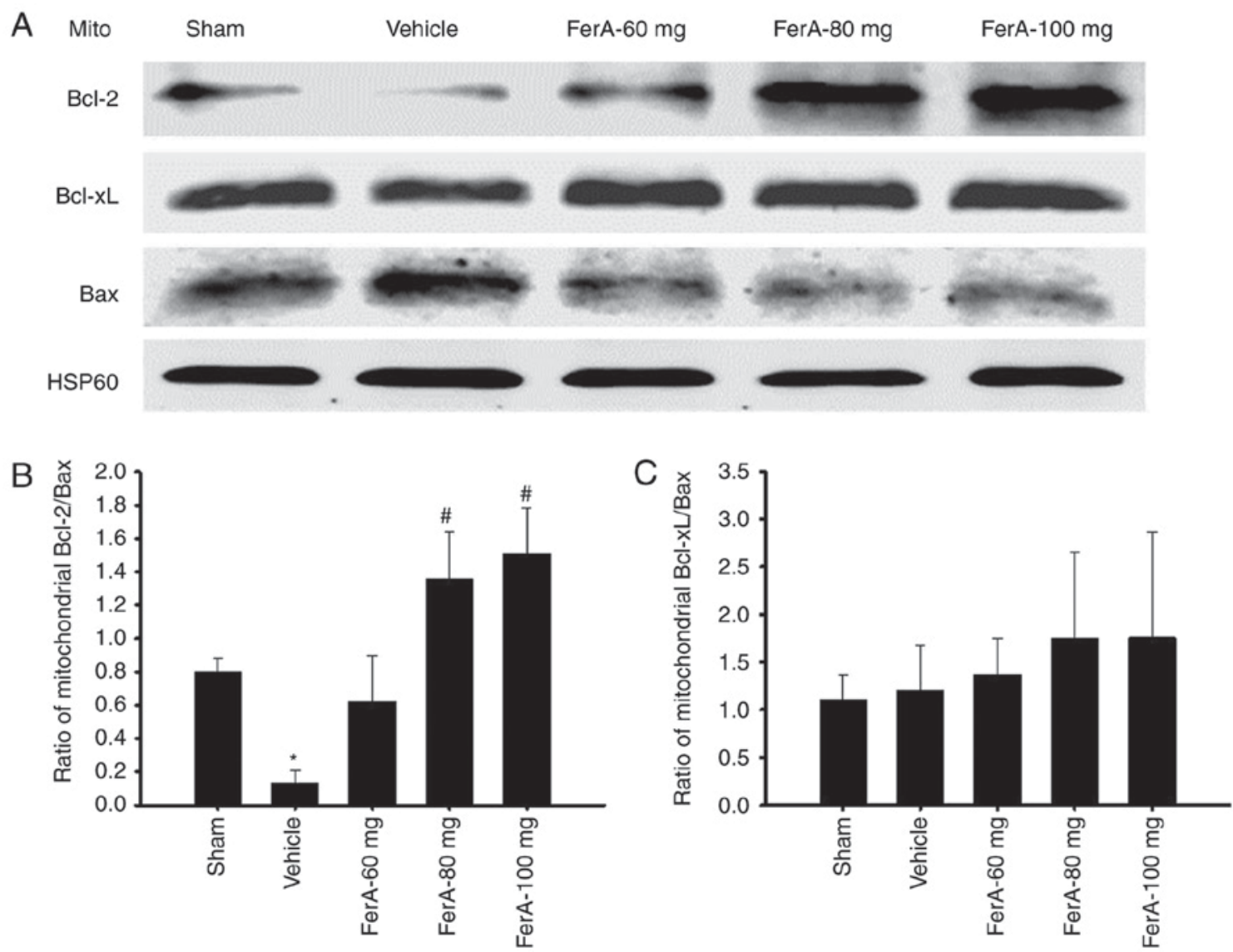

Figure 4. Effects of FerA treatment on the mitochondrial expression of Bcl-2, Bcl-xL, and Bax in the penumbral cortex. (A) Representative western blot images revealed the mitochondrial expression of Bcl-2, Bcl-xL and Bax in the penumbral cortex in the Sham, Vehicle, FerA-60 mg, FerA- $80 \mathrm{mg}$, and FerA-100 mg groups at 7 days post-ischemia. HSP60 was used as an internal control for mitochondrial extracts. The ratios of (B) mitochondrial Bcl-2/Bax and (C) mitochondrial Bcl-xL/Bax expression were measured in the penumbral cortex in the Sham, Vehicle, FerA-60 mg, FerA-80 mg, and FerA-100 mg groups (n=4-5). "P $<0.05$ vs. the Sham group; ${ }^{*} \mathrm{P}<0.05$ vs. the Vehicle group. FerA, ferulic acid; mito, mitochondrial fraction; Bcl-2, B-cell lymphoma-2; Bax, Bcl-2-associated $\mathrm{X}$ protein; Bcl-xL, Bcl-extra-large.

expression between the DS + Vehicle and LY + FerA-100 mg groups $(\mathrm{P}>0.05)$.

Effects of DS + FerA-100 mg and LY + FerA-100 mg on the cerebral infarct area. The percentage cerebral infarct area was significantly increased in the DS + Vehicle group compared with that in the DS + Sham group $(\mathrm{P}<0.05)$ and was significantly reduced in the DS + FerA-100 mg group compared with that in the DS + Vehicle group $(\mathrm{P}<0.05$; Fig. $8 \mathrm{~A}$ and $\mathrm{B})$ at 7 days post-ischemia. No significant differences were observed in the percentage of cerebral infarct areas between the DS + Vehicle and LY + FerA-100 mg groups $(\mathrm{P}>0.05)$.

\section{Discussion}

In permanent focal cerebral ischemia, the infarct area rapidly increases within 1 day following the onset of ischemia and then undergoes delayed infarct expansion between 1 and 7 days post-ischemia $(30,31)$. In the present study, the cerebral infarction areas were calculated in a rat model of permanent MCAo at 7 days post-ischemia. The results, consistent with previous findings on cerebral infarction, revealed that the total infarct area involving the cortex and striatum predominantly developed 7 days following cerebral ischemia and that the neurological status declined between the acute phase (day 1) and the subacute phase (day 7) following permanent MCAo. Previous studies have shown that FerA $(100 \mathrm{mg} / \mathrm{kg})$ administered iv immediately following the onset of ischemia exerted neuroprotective effects against cerebral infarction 1 day following permanent cerebral ischemia $(23,32)$. In the present study, the effects of FerA during the subacute phase of ischemic injury were further investigated, and it was found that FerA administered iv at a dose of 80 (FerA-80 mg) or $100 \mathrm{mg} / \mathrm{kg}$ (FerA-100 mg), but not $60 \mathrm{mg} / \mathrm{kg}$ (FerA-60 mg), immediately following ischemia effectively ameliorated cerebral infarction and improved neurological outcomes 7 days following permanent MCAo.

Increasing evidence has revealed that apoptotic cells present in the ischemic penumbra contribute to infarct expansion during permanent $(30,31,33)$ and transient $(1,28)$ focal cerebral ischemia. Therefore, inhibition of apoptosis in the peri-infarct region leads to the mitigation of delayed infarct expansion in the subacute stage of cerebral ischemia $(1,33)$. Akt signaling is a key regulator of cell death and survival through the activation of various anti-apoptotic pathways during cerebral ischemic injury $(34,35)$. Previous studies have demonstrated that the pharmacological activation of Akt signaling provides neuroprotective effects against apoptosis in the ischemic penumbra and subsequent cerebral infarction in permanent MCAo (36,37). In the present study, the results of 


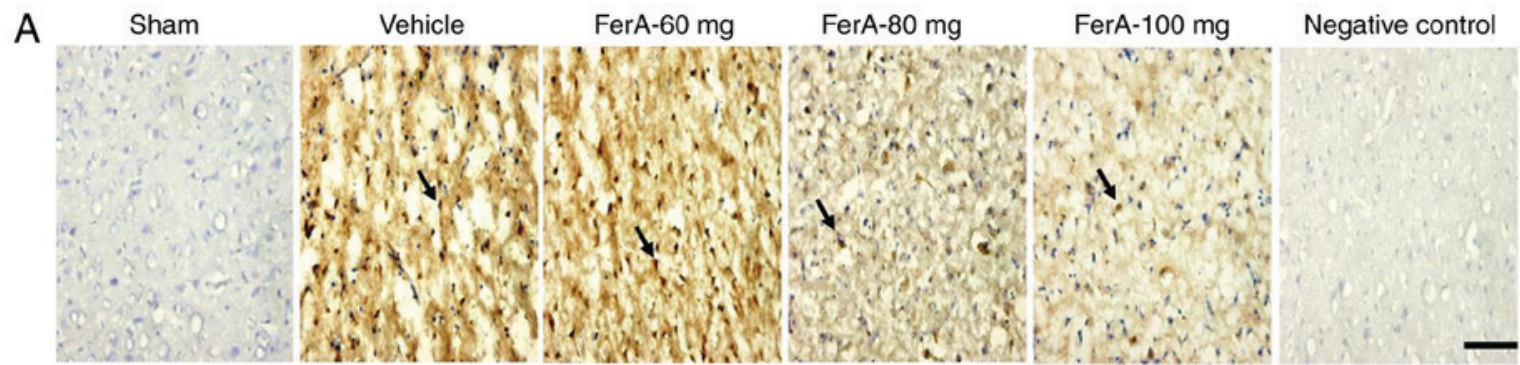

B

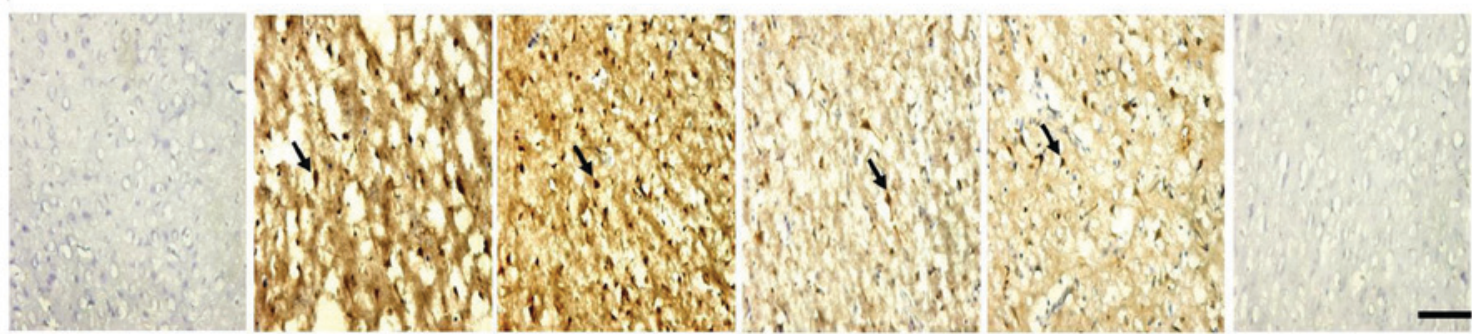

C

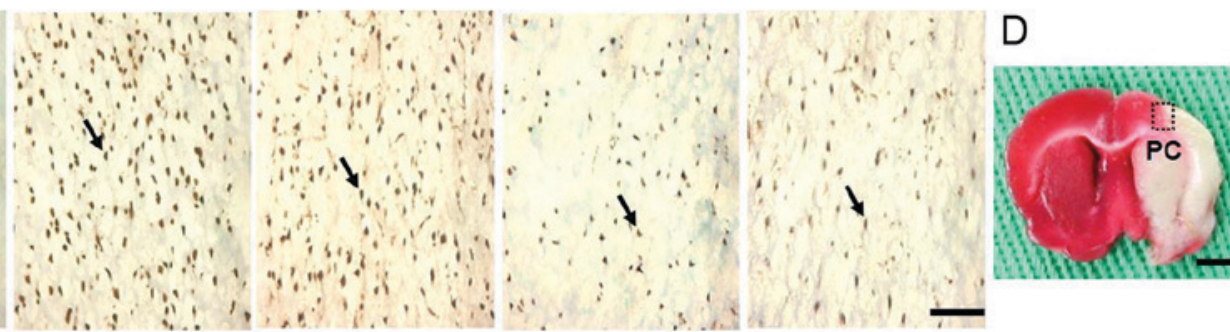

Figure 5. Effects of FerA treatment on the expression of cytochrome $c$-, cleaved caspase-3-, and TUNEL-immunoreactive cells in the PC. Representative images show (A) cytochrome $c$-, (B) cleaved caspase-3- and (C) TUNEL-immunoreactive cells in the PC in the Sham, Vehicle, FerA-60 mg, FerA-80 mg and FerA-100 mg groups at 7 days post-ischemia. Arrows indicate these immunoreactive cells (scale bars=10 $\mu \mathrm{m}$ ). (D) Representative image shows the 2,3,5-triphenyltetrazolium chloride-stained brain coronal section. The dotted square indicates the area of measurement of immunoreactive cells. Dotted square $=1$ mm ${ }^{2}$; scale bar=200 $\mu \mathrm{m}$ ). FerA, ferulic acid; TUNEL, terminal deoxynucleotidyl transferase-mediated dUTP-biotin nick-end labeling; PC, penumbral cortex.

the western blot analysis showed that p-Akt was significantly downregulated in the penumbral cortex following permanent MCAo. However, this decreased expression of p-Akt was effectively restored in the FerA-80 mg and FerA-100 mg groups 7 days following cerebral ischemia. These findings suggest that FerA treatment protects against cerebral ischemic injury in the subacute phase of ischemia, and the neuroprotective effects on cerebral infarction are at least partially attributed to the activation of Akt signaling in the penumbral cortex 7 days following permanent MCAo.

Activated Akt can rapidly phosphorylate certain downstream proteins, including mTOR, and the activity of mTOR is regulated through the phosphorylation of its serine 2448 (14). Akt-dependent activation of the multi-protein complex, including mTOR (mTORC1) causes the phosphorylation of p70S6K and 4E-BP1, its two major downstream targets, which regulate the initiation of translation and protein synthesis (38). During cerebral ischemia, the activation of Akt/mTOR/p70S6K/S6 signaling results in a marked reduction in the ischemic area, leading to the suppression of protein synthesis and exacerbation of neuronal cell death (12). By contrast, the pharmacological upregulation of mTOR/p70S6K signaling protects against apoptosis and cerebral infarction in the acute phase of permanent $(5,13)$ and transient (39) MCAo. Unphosphorylated 4E-BP1 binds to eIF4E with high affinity and prevents it from interacting with eIF4G for the initiation of mRNA translation. By contrast, p-4E-BP1 dissociates from eIF4E, which subsequently binds to eIF4G, resulting in the assembly of translation initiation factors $(40,41)$. Activation of mTOR/4E-BP1 signaling in the peri-infarct region exerts neuroprotective effects against cerebral ischemic injuries in the early phase of ischemic postconditioning (17). The immunoblotting results in the present study indicated that the ratio of $\mathrm{p}-\mathrm{mTOR} / \mathrm{mTOR}$, the expression of 4E-BP1, and the ratio of $\mathrm{p}-4 \mathrm{E}-\mathrm{BP} 1 / 4 \mathrm{E}-\mathrm{BP} 1$ were markedly decreased in the cytosolic fraction in the penumbral cortex, whereas these expression levels were effectively upregulated in the FerA-80 mg and FerA-100 mg groups 7 days following permanent cerebral ischemia. These results are consistent with those of a previous study, in which the upregulated expression of p-mTOR, 4E-BP1 and p-4E-BP1 in the peri-infarct cortex markedly reduced ischemic lesions and improved neurological outcomes in the late phase of permanent MCAo (17). Koh (42) reported that FerA exerted neuroprotective effects against cerebral infarction by activating mTOR/p70S6K/S6 signaling in the ischemic cortex 1 day following permanent MCAo (42). However, in the present study, FerA treatment did not affect the expression of p70S6K or p-p70S6K in the cytosolic fraction in the penumbral cortex 7 days following permanent focal cerebral ischemia. On the basis of these results, it was hypothesized that FerA treatment effectively activates Akt/mTOR survival signaling, and that the beneficial effects of FerA treatment on ischemia-induced cerebral infarction are most likely attributed to the activation of Akt/mTOR/4E-BP1-, but not Akt/mTOR/p70S6K-, induced survival signaling in the penumbral cortex at 7 days following cerebral ischemia. 
Table I. Expression of cytochrome $c$-, cleaved caspase-3-, and TUNEL-immunoreactive cells (count/1 mm²).

\begin{tabular}{lccccc}
\hline Factor & Sham & Vehicle & FerA-60 mg & FerA-80 mg & FerA-100 mg \\
\hline Cytochrome $c$ & $0 \pm 0$ & $322 \pm 26^{\mathrm{a}}$ & $272 \pm 28$ & $129 \pm 21^{\mathrm{b}}$ & $95 \pm 15^{\mathrm{b}}$ \\
Cleaved caspase-3 & $0 \pm 0$ & $258 \pm 55^{\mathrm{a}}$ & $316 \pm 50$ & $112 \pm 5^{\mathrm{b}}$ & $83 \pm 24^{\mathrm{b}}$ \\
TUNEL & $0 \pm 0$ & $818 \pm 110^{\mathrm{a}}$ & $699 \pm 107$ & $366 \pm 65^{\mathrm{b}}$ & $291 \pm 42^{\mathrm{b}}$ \\
\hline
\end{tabular}

${ }^{\mathrm{a}} \mathrm{P}<0.05$ vs. the Sham group; ${ }^{\mathrm{b}} \mathrm{P}<0.05$ vs. the Vehicle group. FerA, ferulic acid; TUNEL, terminal deoxynucleotidyl transferase-mediated dUTP-biotin nick-end labeling.
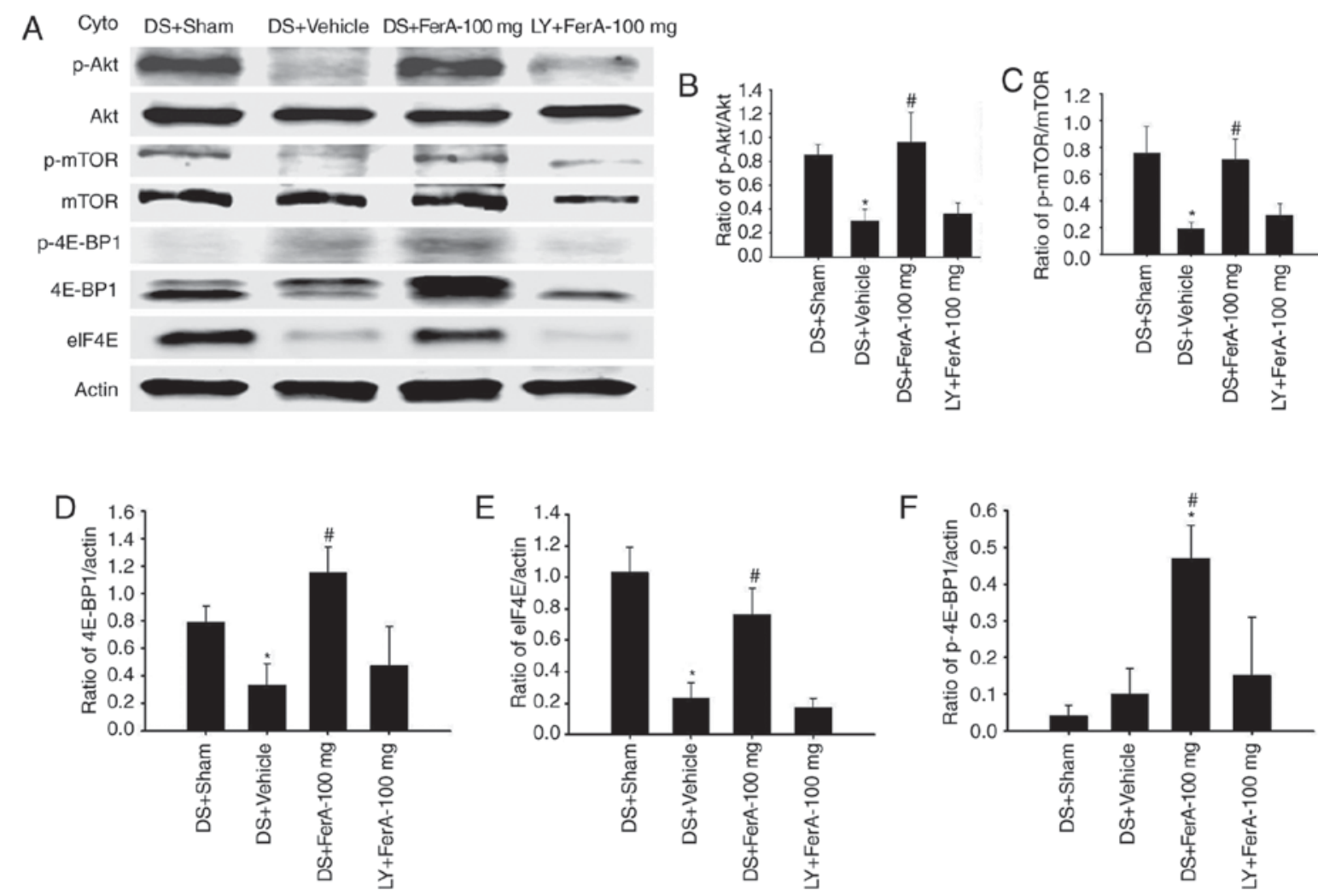

Figure 6. Effects of DS + FerA-100 mg and LY + FerA-100 mg on the cytosolic expression of p-Akt, Akt, p-mTOR, mTOR, p-4E-BP1, 4E-BP1 and eIF4E in the penumbral cortex. (A) Representative images show cytosolic expression of p-Akt, Akt, p-mTOR, mTOR, p-4E-BP1, 4E-BP1, and eIF4E in the penumbral cortex in the DS + Sham, DS + Vehicle, DS + FerA-100 mg, and LY + FerA-100 mg groups at 7 days post-ischemia. The ratios of (B) p-Akt/Akt (C) p-mTOR/mTOR (D) 4E-BP1/actin (E) eIF4E/actin, and (F) p-4E-BP1/actin expression were measured in the penumbral cortex in the DS + Sham, DS + Vehicle, DS + FerA-100 mg, and LY+FerA-100 mg groups ( $\mathrm{n}=4-5) .{ }^{*} \mathrm{P}<0.05$ vs. the DS + Sham group; ${ }^{*} \mathrm{P}<0.05$ vs. the DS + Vehicle group. FerA, ferulic acid; DS, dimethyl sulfoxide; LY, LY294002; cyto, cytosolic fraction; mTOR, mammalian target of rapamycin; eIF4E, eukaryotic initiation factor 4E; 4E-BP1, eIF4E-binding protein 1; p-, phosphorylated.

Accumulating evidence indicates that eIF4E is critical for translational control and is inactivated by stress, including ischemic stress, and activated by survival factors. In addition, the overexpression of eIF4E exerts beneficial effects on cytochrome $c$-mediated apoptosis through the upregulation of anti-apoptotic proteins, including Bcl-2 and Bcl-xL, in various cell lines in vitro (43-45). Fan et al (45) reported that pharmacological inhibition of the eIF4E-eIF4G interaction induced the apoptosis of human lung cancer cell lines in vitro. Under cerebral ischemia conditions, the translocation of pro-apoptotic Bax from the cytosol to the mitochondria disrupts the integrity of the mitochondrial outer membrane, resulting in the release of cytochrome $c$ (46). Cytosolic cytochrome $c$ combines with apoptotic protease activating factor- 1 and
dATP to form the apoptosome. This complex recruits and activates caspase- 9 , which subsequently cleaves the downstream effector caspase-3, thereby triggering cytochrome $c$-mediated apoptosis (47). It has been suggested that the anti-apoptotic $\mathrm{Bcl}-2$ protein $(\mathrm{Bcl}-\mathrm{xL})$ binds to the mitochondrial membrane and preserves mitochondrial outer membrane integrity by preventing the translocation of Bax; thus, Bcl-2 directly inhibits the release of cytochrome $c$ from the mitochondria into the cytosol (48). An increased ratio of mitochondrial Bcl-2 (Bcl-xL)/Bax prevents the translocation of Bax to the mitochondria, promoting cell survival, whereas a decreased ratio of mitochondrial Bcl-2 (Bcl-xL)/Bax induces mitochondrial Bax homo-oligomerization and subsequently causes mitochondrial damage, leading to cytochrome $c$-mediated apoptosis in 

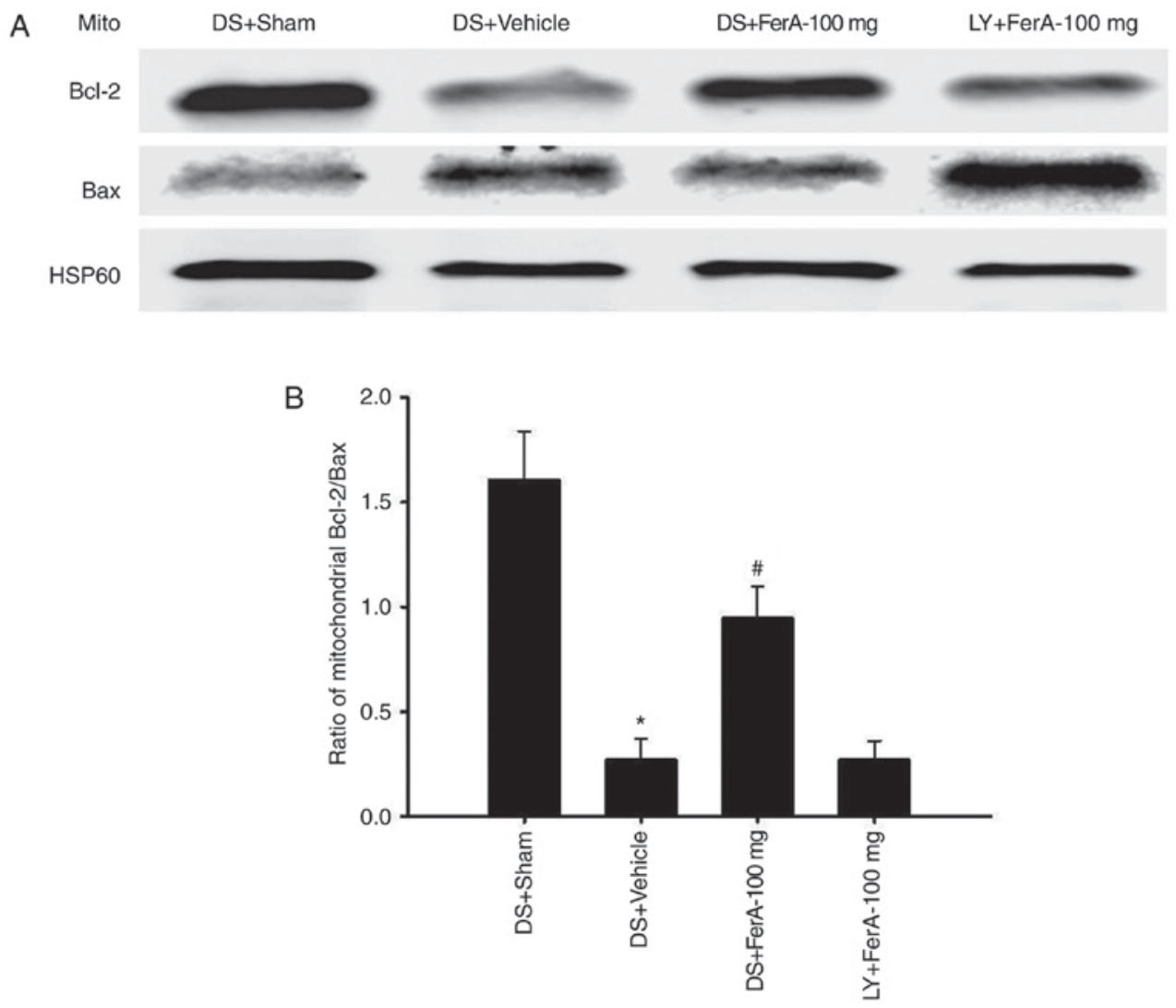

Figure 7. Effects of DS + FerA-100 mg and LY + FerA-100 mg on the mitochondrial expression of Bcl-2 and Bax in the penumbral cortex. (A) Representative images show the mitochondrial expression of Bcl-2 and Bax in the penumbral cortex in the DS + Sham, DS + Vehicle, DS + FerA-100 mg, and LY + FerA-100 mg groups at 7 days post-ischemia. The ratio of (B) mitochondrial Bcl-2/Bax expression was measured in the penumbral cortex in the DS + Sham, DS + Vehicle DS + FerA-100 mg, and LY + FerA-100 mg groups $(\mathrm{n}=4-5)$. ${ }^{*} \mathrm{P}<0.05$ vs. the DS + Sham group; ${ }^{\#} \mathrm{P}<0.05$ vs. the DS + Vehicle group. FerA, ferulic acid; DS, dimethyl sulfoxide; LY, LY294002; Mito, mitochondrial fraction; Bcl-2, B-cell lymphoma-2; Bax, Bcl-2-associated X protein.
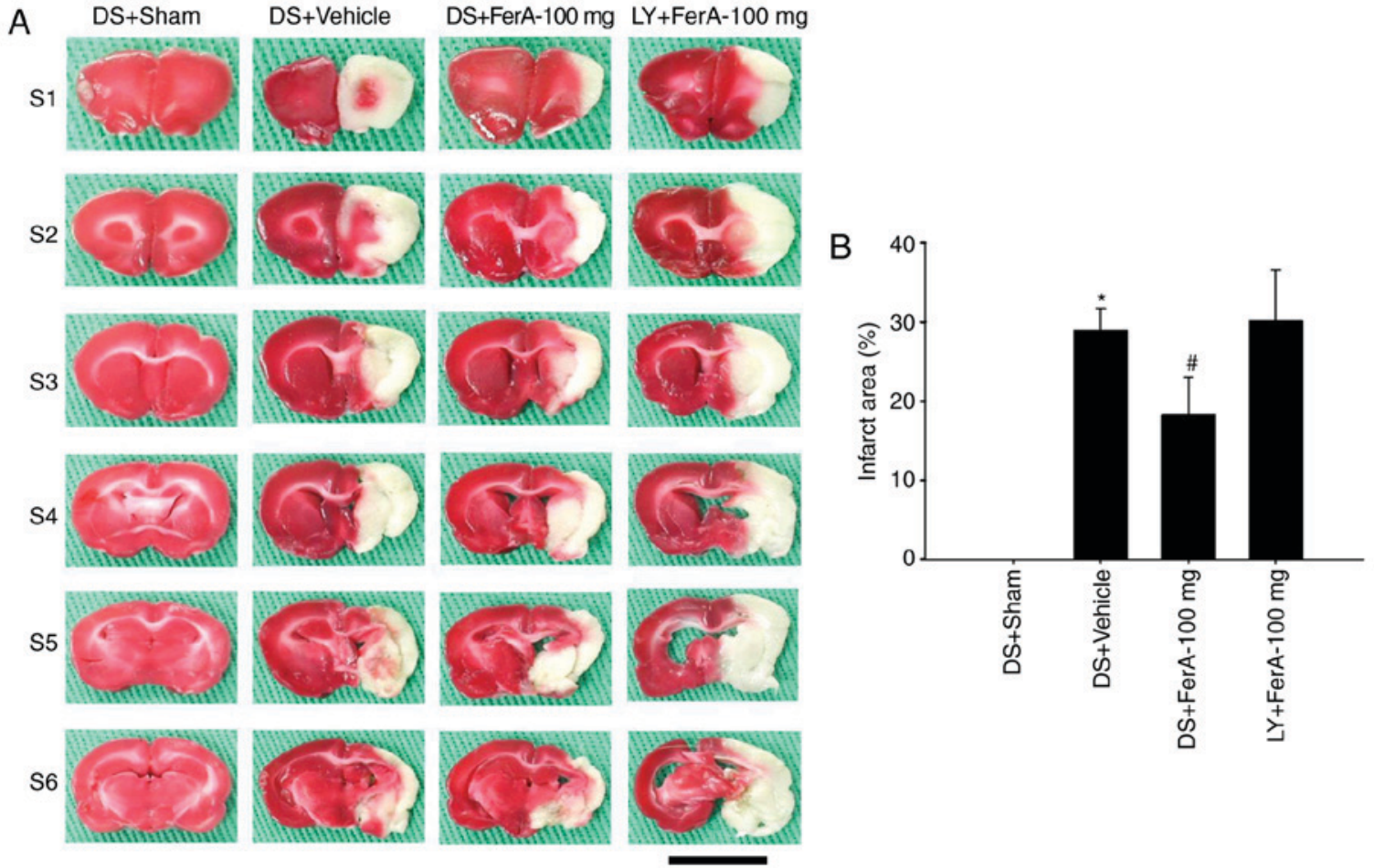

Figure 8. Effects of DS + FerA-100 mg and LY + FerA-100 mg on cerebral infarction. (A) TTC staining reveals normal brain tissues (dark red color) and infarcted tissues (pale-white color) between S1 and S6 (scale bar=1 cm). (B) Percentages of cerebral infarct areas in the DS + Sham, DS + Vehicle, DS + FerA-100 mg, and LY + FerA-100 mg groups were evaluated at 7 days post-ischemia $(n=3) . ~ " P<0.05$ vs. the DS + Sham group; ${ }^{*} \mathrm{P}<0.05$ vs. the $\mathrm{DS}+\mathrm{Vehicle}$ group. FerA, ferulic acid; DS, dimethyl sulfoxide; LY, LY294002. 
the ischemic region following cerebral ischemia $(1,46)$. The results of the present study revealed that the ratio of mitochondrial Bcl-2/Bax expression was significantly decreased in the penumbral cortex following MCAo, whereas the reduced ratio of Bcl-2/Bax expression was effectively upregulated in the FerA-80 mg and FerA-100 mg groups at 7 days post-ischemia. However, FerA treatment did not affect the ratios of mitochondrial Bcl-xL/Bax expression in the penumbral cortex. In the IHC and TUNEL assays, the expression of cytochrome $c$, cleaved caspase-3, and TUNEL immunoreactivity was significantly upregulated in the penumbral cortex following permanent MCAo, however, these increased immunoreactivity levels were effectively downregulated in the FerA-80 mg and FerA-100 mg groups at 7 days post-ischemia. These results appear to coincide with those of a previous study, in which pharmacological treatment exerted a neuroprotective effect against cerebral infarction through the inhibition of cytochrome $c$-mediated apoptosis in the ischemic region, and the anti-apoptotic effect was possibly due to upregulation of the mitochondrial $\mathrm{Bcl}-2 / \mathrm{Bax}$ ratio in the acute phase of permanent cerebral ischemia (49). These findings suggest that the upregulation of Akt/mTOR/4E-BP1-mediated Bcl-2, but not $\mathrm{Bcl}-\mathrm{xL}$, anti-apoptotic cascade may be involved in the neuroprotective effects of FerA-80 mg and FerA-100 mg treatment, and that the effects of FerA against mitochondrial Bax-related apoptosis can be further attributed to inhibition of the cytochrome $c$-mediated caspase- 3 activation pathway in the penumbral cortex 7 days following permanent MCAo.

To determine the precise mechanism underlying the involvement of Akt-mediated anti-apoptotic signaling in FerA treatment, another experiment was performed in the FerA-100 mg group as the representative group of FerA treatment to evaluate the action of LY, a selective inhibitor of PI3K/Akt signaling, 7 days following cerebral ischemia. It was found that $1 \%$ DMSO (vehicle control) pretreatment (DS + Sham, DS + Vehicle, and DS + FerA-100 mg) did not alter the expression of p-Akt, p-mTOR or p-4E-BP1. Furthermore, the expression of eIF4E was markedly decreased in the DS + Vehicle group and the reduced expression of eIF4E was effectively restored in the DS + FerA-100 mg group. However, LY pretreatment (LY + FerA-100 mg) effectively abrogated the upregulating effects of FerA-100 mg treatment on the expression of p-Akt. LY + FerA-100 mg treatment consequently suppressed mTOR/4E-BP1/eIF4E signaling and activated the mitochondrial Bax-related apoptotic signaling cascade in the penumbral cortex, resulting in the exacerbation of the cerebral infarct size 7 days following permanent cerebral ischemia. On the basis of these results, it was hypothesized that FerA treatment exerts beneficial effects on cerebral infarction by activating Akt signaling, and that the downregulating effects of FerA treatment on mitochondrial Bax-induced apoptosis are attributed to the upregulation of the Akt/mTOR/4E-BP1/eIF4E/Bcl-2 anti-apoptotic signaling in the penumbral cortex 7 days following cerebral ischemia. To the best of our knowledge, the present study is the first to show that FerA treatment exerts neuroprotective effects against Bax-induced apoptosis by upregulating Akt/mTOR/4E-BP1-mediated, but not Akt/mTOR/p70S6K-mediated Bcl-2 anti-apoptotic signaling in the subacute phase of permanent MCAo.

Compelling evidence shows that Akt-mediated signaling downregulates the expression of inducible nitric oxide synthase, which elicits nitric oxide (NO)-induced apoptosis in the ischemic region following transient $\operatorname{MCAo}(50,51)$. Previous studies have shown that FerA protects against cerebral ischemic injury by inhibiting NO-induced apoptotic signaling in the acute phase of cerebral ischemia $(18,52)$. However, the role of FerA-induced Akt-mediated signaling in the regulation of nitric oxide synthase during the subacute phase of permanent MCAo requires elucidation in the future.

In conclusion, the findings of the present study suggest that FerA administered at a dose of 80 or $100 \mathrm{mg} / \mathrm{kg}$ immediately following the onset of cerebral ischemia effectively reduces cerebral infarction and improves neurological functions 7 days following cerebral ischemia, and that the anti-infarction effects of FerA treatment are associated with the activation of Akt-mediated anti-apoptotic signaling in the penumbral cortex. The effects of FerA treatment on mitochondrial Bax-induced apoptosis can be further attributed to the upregulation of Akt/mTOR/4E-BP1/Bcl-2 anti-apoptotic signaling, which inhibits the cytochrome $c /$ caspase-3-dependent apoptotic pathway in the penumbral cortex 7 days following permanent focal cerebral ischemia. Evidence indicates that FerA exerts neuroprotective effects against cerebral infarct in the acute phase of permanent cerebral ischemia $(23,32)$. The results of the present study further indicate that FerA treatment exerts beneficial effects on cerebral infarction in the subacute phase of permanent MCAo. Therefore, FerA treatment offers a potential strategy in the subacute phase of permanent focal cerebral ischemia. Previous studies have demonstrated that upregulation of the upstream components of Akt signaling, including tropomyosin receptor kinase B $(53,54)$ and receptor tyrosine kinase (55), effectively attenuates cerebral ischemic injury in rat models of cerebral ischemia. Therefore, further investigations are warranted to characterize the effects of FerA on the regulation of Akt upstream signaling and in the chronic phase of cerebral ischemia for determining its future clinical application.

\section{Acknowledgements}

Not applicable.

\section{Funding}

The present study was supported by grants from China Medical University (grant no. CMU105-S-40) and China Medical University Hospital (grant nos. DMR-105-007 and DMR-107-165), Taichung, Taiwan.

\section{Availability of data and materials}

The datasets used and/or analyzed during the present study are available from the corresponding author on reasonable request.

\section{Authors' contributions}

CYC and YCL designed experiments. CYC performed the experiments, analyzed the data and wrote the manuscript. STK participated in the conception and design of the study, and helped to draft the manuscript. All authors have read and approved the final manuscript. 


\section{Ethics approval and consent to participate}

All study procedures were approved by the Institutional Animal Care and Use Committee of China Medical University (Taichung, Taiwan; permit no. 2016-321).

\section{Patient consent for publication}

Not applicable.

\section{Competing interests}

The authors declare that they have no competing interests.

\section{References}

1. Cheng CY, Tang NY, Kao ST and Hsieh CL: Ferulic acid administered at various time points protects against cerebral infarction by activating p38 MAPK/p90RSK/CREB/Bcl-2 anti-apoptotic signaling in the subacute phase of cerebral ischemia-reperfusion injury in rats. PLoS One 11: e0155748, 2016.

2. Huang H, Zhong R, Xia Z, Song J and Feng L: Neuroprotective effects of rhynchophylline against ischemic brain injury via regulation of the Akt/mTOR and TLRs signaling pathways. Molecules 19: 11196-11210, 2014.

3. Wang M, Li YJ, Ding Y, Zhang HN, Sun T, Zhang K, Yang L, Guo YY, Liu SB, Zhao MG and Wu YM: Silibinin prevents autophagic cell death upon oxidative stress in cortical neurons and cerebral ischemia-reperfusion injury. Mol Neurobiol 53: 932-943, 2016.

4. Zhu H, Zhang Y, Shi Z, Lu D, Li T, Ding Y, Ruan Y and Xu A: The neuroprotection of liraglutide against ischaemia-induced apoptosis through the activation of the PI3K/AKT and MAPK pathways. Sci Rep 6: 26859, 2016.

5. Koh PO: Melatonin prevents ischemic brain injury through activation of the mTOR/p70S6 kinase signaling pathway. Neurosci Lett 444: 74-78, 2008.

6. Xie R, Cheng M, Li M, Xiong X, Daadi M, Sapolsky RM and Zhao $\mathrm{H}$ : Akt isoforms differentially protect against stroke-induced neuronal injury by regulating mTOR activities. J Cereb Blood Flow Metab 33: 1875-1885, 2013.

7. Maiese K, Chong ZZ, Wang S and Shang YC: Oxidant stress and signal transduction in the nervous system with the PI 3-K, Akt, and mTOR cascade. Int J Mol Sci 13: 13830-13866, 2012.

8. Wang C, Wang Z, Zhang X, Dong L, Xing Y, Li Y, Liu Z, Chen L, Qiao $\mathrm{H}$, Wang $\mathrm{L}$ and Zhu C: Protection by silibinin against experimental ischemic stroke: Up-regulated pAkt, pmTOR HIF-1alpha and Bcl-2, down-regulated Bax, NF-kappaB expression. Neurosci Lett 529: 45-50, 2012.

9. Wu C, Fujihara H, Yao J, Qi S, Li H, Shimoji K and Baba H: Different expression patterns of $\mathrm{Bcl}-2, \mathrm{Bcl}-\mathrm{xl}$, and Bax proteins after sublethal forebrain ischemia in C57Black/Crj6 mouse striatum. Stroke 34: 1803-1808, 2003.

10. Chi OZ, Barsoum S, Vega-Cotto NM, Barsoum S, Vega-Cotto NM, Jacinto E, Liu X, Mellender SJ and Weiss HR: Effects of rapamycin on cerebral oxygen supply and consumption during reperfusion after cerebral ischemia. Neuroscience 316: 321-327, 2016.

11. Xie R, Wang P, Cheng M, Sapolsky R, Ji X and Zhao H: Mammalian target of rapamycin cell signaling pathway contributes to the protective effects of ischemic postconditioning against stroke. Stroke 45: 2769-2776, 2014.

12. Koh PO: Gingko biloba extract (EGb 761) prevents cerebral ischemia-induced p70S6 kinase and S6 phosphorylation. Am J Chin Med 38: 727-734, 2010.

13. Koh PO, Cho JH, Won CK, Lee HJ, Sung JH and Kim MO: Estradiol attenuates the focal cerebral ischemic injury through mTOR/p70S6 kinase signaling pathway. Neurosci Lett 436: 62-66, 2008.

14. Chong ZZ, Yao Q and Li HH: The rationale of targeting mammalian target of rapamycin for ischemic stroke. Cell Signal 25: 1598-1607, 2013.

15. Ayuso MI, Hernández-Jiménez M, Martin ME, Salinas M and Alcázar A: New hierarchical phosphorylation pathway of the translational repressor eIF4E-binding protein 1 (4E-BP1) in ischemia-reperfusion stress. J Biol Chem 285: 34355-34363, 2010.
16. Ayuso MI, Martinez-Alonso E, Cid C, Alonso de Leciñana M and Alcázar A: The translational repressor eIF4E-binding protein 2 (4E-BP2) correlates with selective delayed neuronal death after ischemia. J Cereb Blood Flow Metab 33: 1173-1181, 2013.

17. Xie R, Wang P, Ji X and Zhao H: Ischemic post-conditioning facilitates brain recovery after stroke by promoting Akt/mTOR activity in nude rats. J Neurochem 127: 723-732, 2013

18. Koh PO: Ferulic acid modulates nitric oxide synthase expression in focal cerebral ischemia. Lab Anim Res 28: 273-278, 2012.

19. Zhang L, Wang H, Wang T, Jiang N, Yu P, Chong Y and Fu F: Ferulic acid ameliorates nerve injury induced by cerebral ischemia in rats. Exp Ther Med 9: 972-976, 2015.

20. Wu YC and Hsieh CL: Pharmacological effects of radix angelica sinensis (Danggui) on cerebral infarction. Chin Med 6: 32, 2011.

21. Cheng CY, Ho TY, Lee EJ, Su SY, Tang NY and Hsieh CL: Ferulic acid reduces cerebral infarct through its antioxidative and anti-inflammatory effects following transient focal cerebral ischemia in rats. Am J Chin Med 36: 1105-1119, 2008.

22. Cheng CY, Su SY, Tang NY, Ho TY, Chiang SY and Hsieh CL: Ferulic acid provides neuroprotection against oxidative stress-related apoptosis after cerebral ischemia/reperfusion injury by inhibiting ICAM-1 mRNA expression in rats. Brain Res 1209: 136-150, 2008.

23. Koh PO: Ferulic acid prevents the cerebral ischemic injury-induced decrease of Akt and Bad phosphorylation. Neurosci Lett 507: 156-160, 2012.

24. Koh PO: Ferulic acid prevents the cerebral ischemic injury-induced decreases of astrocytic phosphoprotein PEA-15 and its two phosphorylated forms. Neurosci Lett 511: 101-105, 2012.

25. Longa EZ, Weinstein PR, Carlson S and Cummins R: Reversible middle cerebral artery occlusion without craniectomy in rats. Stroke 20: 84-91, 1989.

26. Chen J, Sanberg PR, Li Y, Wang L, Lu M, Willing AE, Sanchez-Ramos J and Chopp M: Intravenous administration of human umbilical cord blood reduces behavioral deficits after stroke in rats. Stroke 32: 2682-2688, 2001.

27. Hsiang CY, Wu SL and Ho TY: Morin inhibits 12-O-tetradecanoylphorbol-13-acetate-induced hepatocellular transformation via activator protein 1 signaling pathway and cell cycle progression. Biochem Pharmacol 69: 1603-1611, 2005.

28. Cheng CY, Lin JG, Tang NY, Kao ST and Hsieh CL: Electroacupuncture-like stimulation at the Baihui (GV20) and Dazhui (GV14) acupoints protects rats against subacute-phase cerebral ischemia-reperfusion injuries by reducing S100B-mediated neurotoxicity. PLoS One 9: e91426, 2014.

29. Cheng CY, Lin JG, Su SY, Tang NY, Kao ST and Hsieh CL: Electroacupuncture-like stimulation at Baihui and Dazhui acupoints exerts neuroprotective effects through activation of the brain-derived neurotrophic factor-mediated MEK1/2/ERK1/2/p90RSK/bad signaling pathway in mild transient focal cerebral ischemia in rats. BMC Complement Altern Med 14: 92, 2014.

30. Matsui T, Mori T, Tateishi N, Kagamiishi Y, Satoh S, Katsub N, Morikawa E, Morimoto T, Ikuta F and Asano T: Astrocytic activation and delayed infarct expansion after permanent focal ischemia in rats. Part I: Enhanced astrocytic synthesis of $\mathrm{s}-100 \mathrm{beta}$ in the periinfarct area precedes delayed infarct expansion. J Cereb Blood Flow Metab 22: 711-722, 2002.

31. Mori T, Town T, Kobayashi M, Tan J, Fujita SC and Asano T: Augmented delayed infarct expansion and reactive astrocytosis after permanent focal ischemia in apolipoprotein E4 knock-in mice. J Cereb Blood Flow Metab 24: 646-656, 2004.

32. Koh PO: Ferulic acid attenuates the injury-induced decrease of protein phosphatase $2 \mathrm{~A}$ subunit $\mathrm{B}$ in ischemic brain injury. PLoS One 8: e54217, 2013

33. Tateishi N, Mori T, Kagamiishi Y, Satoh S, Katsube N, Morikawa E, Morimoto T, Matsui T and Asano T: Astrocytic activation and delayed infarct expansion after permanent focal ischemia in rats. Part II: Suppression of astrocytic activation by a novel agent (R)-(-)-2-propyloctanoic acid (ONO-2506) leads to mitigation of delayed infarct expansion and early improvement of neurologic deficits. J Cereb Blood Flow Metab 22: 723-734, 2002.

34. Tang Q, Han R, Xiao H, Shen J, Luo Q and Li J: Neuroprotective effects of tanshinone IIA and/or tetramethylpyrazine in cerebral ischemic injury in vivo and in vitro. Brain Res 1488: 81-91, 2012.

35. Shi J, Gu JH, Dai CL, Gu J, Jin X, Sun J, Iqbal K, Liu F and Gong CX: O-GlcNAcylation regulates ischemia-induced neuronal apoptosis through AKT signaling. Sci Rep 5: 14500, 2015. 
36. Wu J, Li J, Hu H, Liu P, Fang Y and Wu D: Rho-kinase inhibitor, fasudil, prevents neuronal apoptosis via the Akt activation and PTEN inactivation in the ischemic penumbra of rat brain. Cell Mol Neurobiol 32: 1187-1197, 2012.

37. Ishrat T, Sayeed I, Atif F, Hua F and Stein DG: Progesterone is neuroprotective against ischemic brain injury through its effects on the phosphoinositide 3-kinase/protein kinase B signaling pathway. Neuroscience 210: 442-450, 2012.

38. Bracho-Valdés I, Moreno-Alvarez P, Valencia-Martinez I, Robles-Molina E, Chavez-Vargas L and Vázquez-Prado J: mTORC1- and mTORC2-interacting proteins keep their multifunctional partners focused. IUBMB Life 63: 896-914, 2011.

39. Li W, Yang Y, Hu Z, Ling S and Fang M: Neuroprotective effects of DAHP and Triptolide in focal cerebral ischemia via apoptosis inhibition and PI3K/Akt/mTOR pathway activation. Front Neuroanat 9: 48, 2015.

40. Josse L, Xie J, Proud CG and Smales CM: mTORC1 signalling and eIF4E/4E-BP1 translation initiation factor stoichiometry influence recombinant protein productivity from GS-CHOK1 cells. Biochem J 473: 4651-4664, 2016.

41. Hay N and Sonenberg N: Upstream and downstream of mTOR. Genes Dev 18: 1926-1945, 2004.

42. Koh PO: Ferulic acid attenuates focal cerebral ischemia-induced decreases in p70S6 kinase and S6 phosphorylation. Neurosci Lett 555: 7-11,2013.

43. Attar-Schneider O, Pasmanik-Chor M, Tartakover-Matalon S, Drucker L and Lishner M: eIF4E and eIF4GI have distinct and differential imprints on multiple myeloma's proteome and signaling. Oncotarget 6: 4315-4329, 2015.

44. Li S, Perlman DM, Peterson MS, Burrichter D, Avdulov S, Polunovsky VA and Bitterman PB: Translation initiation factor 4E blocks endoplasmic reticulum-mediated apoptosis J Biol Chem 279: 21312-21317, 2004.

45. Fan S, Li Y, Yue P, Khuri FR and Sun SY: The eIF4E/eIF4G interaction inhibitor 4EGI-1 augments TRAIL-mediated apoptosis through c-FLIP Down-regulation and DR5 induction independent of inhibition of cap-dependent protein translation Neoplasia 12: 346-356, 2010.

46. Cao G, Minami M, Pei W, Yan C, Chen D, O'Horo C, Graham SH and Chen J: Intracellular Bax translocation after transient cerebral ischemia: Implications for a role of the mitochondrial apoptotic signaling pathway in ischemic neuronal death. J Cereb Blood Flow Metab 21: 321-333, 2001.
47. Noshita N, Sugawara T, Fujimura M, Morita-Fujimura Y and Chan PH: Manganese superoxide dismutase affects cytochrome $c$ release and caspase-9 activation after transient focal cerebral ischemia in mice. J Cereb Blood Flow Metab 21: 557-567, 2001.

48. Li L, Peng L and Zuo Z: Isoflurane preconditioning increases B-cell lymphoma-2 expression and reduces cytochrome $c$ release from the mitochondria in the ischemic penumbra of rat brain. Eur J Pharmacol 586: 106-113, 2008.

49. Liu D, Lu C, Wan R, Auyeung WW and Mattson MP Activation of mitochondrial ATP-dependent potassium channels protects neurons against ischemia-induced death by a mechanism involving suppression of Bax translocation and cytochrome $c$ release. J Cereb Blood Flow Metab 22: 431-443, 2002.

50. Lee HK, Jang JY, Yoo HS and Seong YH: Neuroprotective effect of phytoceramide against transient focal ischemia-induced brain damage in rats. Arch Pharm Res 38: 2241-2350, 2015.

51. Zheng L, Ding J, Wang J, Zhou C and Zhang W: Effects and mechanism of action of inducible nitric oxide synthase on apoptosis in a rat model of cerebral ischemia-reperfusion injury. Anat Rec 299: 246-255, 2016.

52. Cheng CY, Su SY, Tang NY, Ho TY, Lo WY and Hsieh CL: Ferulic acid inhibits nitric oxide-induced apoptosis by enhancing $\mathrm{GABA}(\mathrm{B} 1)$ receptor expression in transient focal cerebral ischemia in rats. Acta Pharmacol Sin 31: 889-899, 2010.

53. Yao RQ, Qi DS, Yu HL, Liu J, Yang LH and Wu XX: Quercetin attenuates cell apoptosis in focal cerebral ischemia rat brain via activation of BDNF-TrkB-PI3K/Akt signaling pathway. Neurochem Res 37: 2777-2786, 2012.

54. Qi D, Ouyang C, Wang Y, Zhang S, Ma X, Song Y, Yu H, Tang J, Fu W, Sheng L, et al: HO-1 attenuates hippocampal neurons injury via the activation of BDNF-TrkB-PI3K/Akt signaling pathway in stroke. Brain Res 1577: 69-76, 2014.

55. Zhao H, Shimohata T, Wang JQ, Sun G, Schaal DW, Sapolsky RM and Steinberg GK: Akt contributes to neuroprotection by hypothermia against cerebral ischemia in rats. J Neurosci 25 : 9794-9806, 2005. 